\title{
Neuro-modulating effects of honokiol: a review
}

\author{
Anna Woodbury ${ }^{1}$, Shan Ping Yu ${ }^{1,2}$, Ling Wei ${ }^{1}$ and Paul García ${ }^{1,2}$ \\ 1 Department of Anesthesiology, Emory University, Atlanta, GA, USA \\ 2 Department of Anesthesiology, Veteran Affairs Medical Center, Atlanta, GA, USA
}

Edited by:

Eero Vasar, University of Tartu, Estonia

Reviewed by:

Andrew Harkin, Trinity College Dublin, Ireland

Eduard Maron, University of Tartu,

Estonia

Sulev Köks, University of Tartu,

Estonia

Peter Sidaway, Saga University, Japan

*Correspondence:

Anna Woodbury, Department of

Anesthesiology, Emory University

Hospital, 3B South Emory University

Hospital, 1364 Clifton Road NE,

Atlanta, GA 30322, USA

e-mail: awoodbu@emory.edu
Honokiol is a poly-phenolic compound that exerts neuroprotective properties through a variety of mechanisms. It has therapeutic potential in anxiety, pain, cerebrovascular injury, epilepsy, and cognitive disorders including Alzheimer's disease. It has been traditionally used in medical practices throughout much of Southeast Asia, but has now become more widely studied due to its pleiotropic effects. Most current research regarding this compound has focused on its chemotherapeutic properties. However, it has the potential to be an effective neuroprotective agent as well. This review summarizes what is currently known regarding the mechanisms involved in the neuroprotective and anesthetic effects of this compound and identifies potential areas for further research.

\section{Keywords: honokiol, neuroprotection, GABA, stroke, inflammatory pain, amyloid, magnolol, analgesia}

\section{INTRODUCTION}

Honokiol is a naturally occurring, pleiotropic lignan that can be extracted from Magnolia grandiflora, a species of magnolia common to Japan, and is used in traditional medicines throughout much of Asia. This compound has also been found in several other Magnolia species, including Magnolia dealbata, an endangered endemic species found in Mexico (1-3). Like the flavorful tannins present in wine, honokiol, and its structural analog, magnolol, are poly-phenolic compounds; both with a fragrant and spicy odor. Although aromaticity is not uncommon among anesthetics (lidocaine, propofol, etomidate, etc.) only propofol has a phenol ring like honokiol and magnolol. The structural homology likely explains some of the similar pharmacologic action (Table 1) $(4,5)$.

Honokiol is known for its anxiolytic (6-9), analgesic (10), antidepressant $(11,12)$, antithrombotic (13), antimicrobial (14-16), antispasmodic (17), anti-tumorigenic, and neuroprotective properties (18-27). While its pharmacokinetics have been studied in rodent models, these parameters have yet to be defined in humans (28). In rats, i.v. injection of honokiol $5-10 \mathrm{mg} / \mathrm{kg}$ has a plasma $t_{1 / 2}$ of approximately $40-60 \mathrm{~min}$ (29). Meanwhile, intraperitoneal injection in mice of $250 \mathrm{mg} / \mathrm{kg}$ has yielded a $t_{1 / 2}$ of $4-6 \mathrm{~h}$, with a $t_{\max }$ of about 20-30 $\mathrm{min}(30)$. Due to its gaining popularity in western medical research, honokiol has been modified and synthesized for delivery through various modalities, including oral, intravenous, liposomal, and transdermal preparations (31-33). Honokiol may have some benefits in the peri-operative period, not only for its anxiolytic, analgesic, and antimicrobial effects, but also specifically for its potential role in neurologic and oncologic procedures. This review focuses primarily on honokiol's effects in the central and peripheral nervous systems and its role in neuroprotection as related to its anxiolytic, analgesic, and anti-inflammatory actions.

\section{NEUROPROTECTION}

It is known that honokiol can readily cross the blood brain barrier in order to exert its anti-tumorigenic effects in the central nervous system $(34,35)$. It might be assumed that because of its accessibility to neuronal tissue, honokiol has direct beneficial effects on cellular health as opposed to neuroprotection via promotion of alternate endogenous pathways. However, honokiol appears to exert its neuroprotective effects through a wide range of mechanisms (Figure 1).

In pre-clinical investigations, honokiol has been found to mitigate the effects of stroke and seizure and improve performance on learning and memory tests in behavioral models. Liou et al. administered honokiol intravenously either pre-ischemia [i.e., $15 \mathrm{~min}$ before unilateral middle cerebral artery (MCA) occlusion] or post-ischemia (i.e., administered upon removal of both common carotid arteries clips). Intravenous infusion of honokiol $10^{-4}$ and $10^{-3} \mathrm{mg} / \mathrm{kg}$ in both groups significantly reduced the total volume of infarction without creating significant hemodynamic changes (25). A subsequent study involved administration of intravenous honokiol $15 \mathrm{~min}$ before or $60 \mathrm{~min}$ after MCA occlusion leading to a dose-dependent reduction of the infarct volume by $20-70 \%$ (26). Similarly, in a rodent model of seizure disorder, the behavioral and neurotoxic effects of injection of NMDA into the cerebral ventricular system following acute seizure were measured by impairments in locomotion, climbing, and rotarod performance. These neurotoxic impairments were ameliorated by treatment with honokiol alone or combined with the NMDA antagonist, memantine. Tea polyphenol or memantine alone only partially ameliorated these behavioral impairments, indicating a comparatively augmented neuroprotective role for honokiol in seizure disorder (36).

Honokiol's neuroprotective effects may be related to the promotion of healthy connections among nerve cells, as honokiol and its synthetic analogs have potent neurotrophic activity in vitro 
Table 1 | Structure and properties of phenolic compounds with neuroprotective bio-activity.

\begin{tabular}{|c|c|c|c|}
\hline & Propofol & Honokiol & Magnolol \\
\hline \multicolumn{4}{|l|}{ Chemical structure } \\
\hline Solubility & Lipid & Lipid & Lipid \\
\hline Receptors with known activity & $\mathrm{GABA}_{A}, \mathrm{Na}^{+}$channel & $\mathrm{GABA}_{\mathrm{A}}, \mathrm{NFkB}, \mathrm{NMDA}$ & $\mathrm{GABA}_{A}, \mathrm{NFkB}, \mathrm{NMDA}$ \\
\hline Applications & $\begin{array}{l}\text { Sedative-hypnotic, anti-emetic, } \\
\text { neuroprotectant }\end{array}$ & $\begin{array}{l}\text { Anxiolytic, analgesic, anti-inflammatory, } \\
\text { anti-tumor, neuroprotectant }\end{array}$ & $\begin{array}{l}\text { Antibacterial, antioxidant, } \\
\text { anti-inflammatory, neuroprotectant }\end{array}$ \\
\hline
\end{tabular}

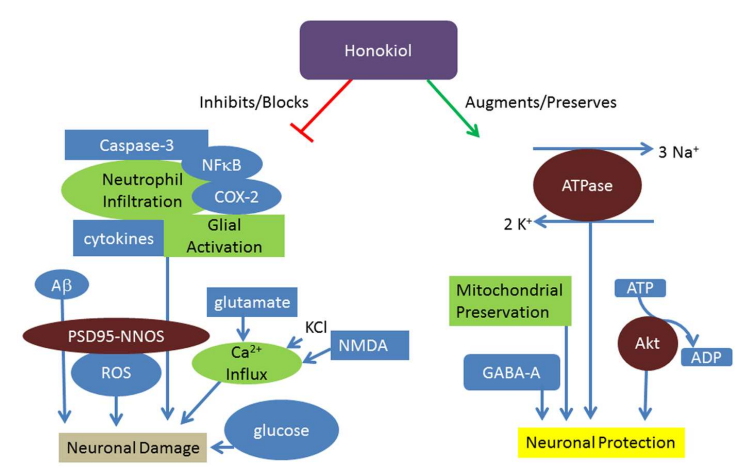

FIGURE 1 | Honokiol promotes neuroprotection through various mechanisms. Honokiol results in neuronal protection through preservation of $\mathrm{Na}^{+} / \mathrm{K}^{+}$ATPase, phosphorylation of pro-survival factors, preservation of mitochondria, and modulation of $\mathrm{GABA}_{\mathrm{A}}$. Honokiol further promotes neuronal health through prevention of glucose, ROS, and inflammatory mediated damage.

(37-39). Several putative pathways for neuroprotection have been investigated including inhibition of the immune system and oxidative stress pathways. For example, Chen et al. suggest that honokiol preserves $\mathrm{Na}^{+} / \mathrm{K}^{+}$-ATPase activity and enzymatic mitochondrial function in mice (19). Meanwhile, Harada et al. suggest that protection post-ischemia by honokiol can be attributed to suppressing the development of post-ischemic glucose intolerance and subsequent neuronal damage (21). In rats, Liou et al. found that honokiol also ameliorates cerebral infarction from ischemia-reperfusion injury via inhibition of neutrophil infiltration and reactive oxygen species (ROS) production as measured by luminol amplified chemiluminescence in neutrophils $(25,26)$. Another group examined the effects of honokiol following cerebral-ischemia-reperfusion injury, and determined that disruption of the postsynaptic density protein PSD95 and calciumdependent neuronal nitric oxide synthase (nNOS) interface is the primary mechanism of honokiol's protective effect, since PSD95nNOS coupling to the NMDA receptor allows neurotoxic calcium influx through the NMDA receptor channels and could thereby result in neurotoxicity (23). Recently, inducers of the inflammatory cascade have been implicated in honokiol's neuroprotective properties as well. Specifically, honokiol inhibits the inflammatory reaction during cerebral-ischemia-reperfusion by suppressing glial NFKB activation and cytokine production (27). Thus, it seems that honokiol may exert its neuroprotective effects during and after cerebral ischemic injury through a variety of mechanisms.

In addition to its potential role in stroke therapy, honokiol may have a role in seizure prevention as well. Honokiol's central depressant activity was first described in the 1980s (40). Subsequently, both honokiol and magnolol have been evaluated as potential therapies for epilepsy and related disorders. Using rat cerebellar granule cells, Lin et al. observed the ability of honokiol to inhibit repetitive firing by blocking glutamate, NMDA and $\mathrm{K}^{+}$ evoked cationic influx. Other studies using intraperitoneal injections of honokiol or magnolol ( 1 and $5 \mathrm{mg} / \mathrm{kg}$ ) were determined to increase seizure threshold with intravenous infusion of NMDA $(10 \mathrm{mg} / \mathrm{ml})$. Although both compounds significantly increased seizure thresholds, honokiol appeared to be more potent (41).

The potential for honokiol to promote cognitive health has been further investigated using neuronal cultures and animal models designed to test learning and memory. Oral honokiol $(1 \mathrm{mg} / \mathrm{kg})$ and magnolol $(10 \mathrm{mg} / \mathrm{kg})$ prevented the age-related memory and learning deficits found in senescence-accelerated mice by preserving cholinergic neurons and enhancing phosphorylation and activity of Akt, a member of the pro-survival pathway (42). Hoi et al. examined nine isolated compounds from Chinese herbs (honokiol, magnolol, vitamin E, salidroside, bilobalide, baicolin, gastrodin, $\alpha$-asarone, and $\beta$-asarone) for potential anti-Alzheimer's activity in neuronal cultures, but only honokiol and magnolol significantly decreased $\beta$-amyloid $(\mathrm{A} \beta$ )-induced neuronal death (22). Decreased ROS production, suppressed intracellular calcium elevation, and inhibition of caspase-3 activity may all contribute to honokiol's neuroprotective effects in $A \beta$ toxicity. The potential for honokiol to be therapeutic for neurodegenerative disease is supported by evidence that a honokiol-containing extract of Magnolia officinalis $(10 \mathrm{mg} / \mathrm{kg}$ in $0.05 \%$ ethanol) prevents lipopolysaccharide (LPS)induced memory deficiency via its antineuroinflammatory and antiamyloidogenic effects (43). 


\section{ANXIOLYSIS AND SLEEP}

Honokiol's central depressant effects may contribute not only to its anticonvulsant activity but also to its anxiolytic activity at low doses. This can be partially attributed to its interaction with the $\mathrm{GABA}_{\mathrm{A}}$ receptor, a known target for benzodiazepines and other anxiolytics. When Kuribara et al. examined the effects of orally administered honokiol in an animal behavior model, they showed that a single oral dose of honokiol increased exploratory behavior while decreasing anxiety-related behavior. This effect was observed with repeated doses as low as $0.2 \mathrm{mg} / \mathrm{kg}$. Honokiol achieved this with less motor or cognitive side effects than oral diazepam. This effect of honokiol was inhibited by administration of subcutaneous flumazenil, bicuculline $\left(\mathrm{a} G \mathrm{GAA}_{\mathrm{A}}\right.$ receptor antagonist), CCK-4, and caffeine. Flumazenil and bicuculline likewise disrupted the anxiolytic effect of diazepam, but CCK-4 and caffeine co-administration with diazepam had quite different outcomes. The combined administration of diazepam with caffeine enhanced diazepam's anxiolytic effect, and diazepam completely reversed the effect of CCK-4. The authors concluded that honokiol produces anxiolysis with a better side effect profile than diazepam, and based on their results with caffeine, possibly through alternative pathways (9). Certain ortho (C2) and para (C4) substitutions increase the GABA-potentiating activity of phenols, and honokiol and magnolol have shown specific selectivity for different $G_{A B A}$ receptor subtypes $(44,45)$. Taferner et al. examined modulation of $\mathrm{GABA}_{\mathrm{A}}$ receptors by honokiol and derivatives as well, looking at subtype selectivity and structure-activity and finding a potential role of the acetamido group in subunit-dependent receptor modulation (46).

Glutamic acid decarboxylase (GAD) is an enzyme involved in GABA synthesis, and the activity of hippocampal GAD was significantly increased in honokiol-treated mice, suggesting that honokiol may alter the brain's synthesis of GABA (47). Because $\mathrm{GABA}_{\mathrm{A}}$ receptors have subunit heterogeneity that influences their function, Alexeev et al. explored the activity of magnolol and honokiol on neuronal and recombinant $\mathrm{GABA}_{\mathrm{A}}$ receptors. Both compounds enhanced GABA-ergic neurotransmission in hippocampal dentate granule neurons. All recombinant receptors were sensitive to modulation, regardless of the subunit subtype, however, both compounds showed higher efficacy at receptors containing the $\delta$ subunit (900-1100\% response with a tertiary $\delta$ subunit vs. $300-500 \%$ response with $\alpha, \beta$, and $\gamma$ subunits only) (48).

A recent study sought to explore the effect of honokiol on sleep. Honokiol ( 10 and $20 \mathrm{mg} / \mathrm{kg}$ ) was found to significantly shorten sleep latency and to increase the amount of non-rapid eye movement sleep, though it had no effect on either the amount of rapid eye movement sleep or EEG power density. This group also found that honokiol excited sleep-promoting neurons in the ventrolateral preoptic areas (49). The sleep-promoting and anxiolytic effects of honokiol suggest a potential additional role for this neolignan in the anesthetic arena.

\section{PAIN AND INFLAMMATION}

Because of honokiol's immunomodulatory effects, it is reasonable to assume that honokiol could be effective in inflammatory pain states. Formalin-induced paw licking is a common model for chronic inflammatory pain. Formalin produces a biphasic pain response following intraplantar injection, resulting in an acute pain phase that lasts approximately $5 \mathrm{~min}$ immediately following formalin injection, and an inflammatory pain phase that is observed $30-45 \mathrm{~min}$ following formalin injection, as evidenced by increased paw-licking behavior (50). Lin et al. showed that honokiol and magnolol reduced the inflammatory phase of formalin-induced paw-licking in mice and decreased formalininduced c-Fos protein expression in superficial (I-II) laminae of the L4-L5 lumbar dorsal horn (51). This same group later studied the effects of honokiol and magnolol on paw-licking and thermal hyperalgesia induced by glutamate receptor agonists injected into the hind paws of mice. They found that honokiol and magnolol were similar in their ability to block the pain responses induced by glutamate, substance P, and PGE2, but honokiol was more selective than magnolol for inhibition of NMDA-induced licking behavioral and thermal hyperalgesia. For example, the same dose of either honokiol or magnolol $(10 \mathrm{mg} / \mathrm{kg})$ reduced glutamate-induced licking time and increased the latency to paw withdrawal from hot water in a test of thermal hyperalgesia. Additionally, intraplantar injection of honokiol or magnolol reduced total licking time and thermal hyperalgesia induction by NMDA in a dose-dependent fashion. Although in substance $\mathrm{P}$ - induced thermal hyperalgesia, magnolol was found to be slightly more effective than honokiol at lower doses, for PGE2-induced nociception and hyperalgesia, honokiol significantly decreased behavioral responses to pain at lower doses than magnolol. At physiologically relevant dosages, both compounds were able to significantly attenuate PGE2-induced thermal hyperalgesia up to $120 \mathrm{~min}$ following pain induction (10).

In an effort to probe deeper into honokiol's anti-inflammatory effects, Chao et al. used LPS to induce inflammation and found that honokiol decreased tumor necrosis factor-alpha secretion in mouse macrophages following LPS. Additionally, honokiol inhibited nitric oxide expression in macrophages, protein kinase $\mathrm{C}-\alpha$ membrane translocation, and NF- $\kappa \mathrm{B}$ activation (52). This anti-inflammatory action can be translated to human monocytederived dendritic cells (53). These studies are supported by work from Murakami et al. who found similar inhibitory effects of honokiol on NF- $\kappa$ B activation and COX-2 expression (54).

Thus, it seems that honokiol's analgesic effects are multifactorial, likely involving the inflammatory cascade, the NMDA receptor, and inhibition of well-known inflammatory pain mediators (e.g., glutamate and substance P). Honokiol would likely be a useful adjunct for treatment of inflammatory pain states, once its side effect profile has been adequately elucidated.

\section{FUTURE DIRECTIONS AND POTENTIAL RISKS}

Honokiol appears to have several potential roles as a therapeutic for anesthesiologists, neurologists, and pain physicians. Although it has been used in traditional medicines for thousands of years, a thorough understanding of its bio-activity will aid in applying this compound or its derivatives to human pathologic conditions. It appears to specifically target tumorous cells in the CNS while preserving and protecting healthy neurons and preventing deleterious results from ischemia, seizure, amyloidosis, anxiety, depression, and pain $(8,9,11,12,22,28,35,55,56)$. It is possible that many of honokiol's downstream anti-inflammatory effects 
could result from modulation at a single upstream site that is yet to be elucidated. Its lipid solubility likely further contributes to its ability to act at multiple sites by allowing the compound to cross lipid bi-layers and exert its action intracellularly and beyond the blood brain barrier. Perhaps the reason for honokiol's pleiotropic effects can be attributed partially to its chemical structure, which allows it certain similarities to propofol. Polyphenols, like phenols, are small compounds capable of interacting with several membrane proteins through hydrogen bonding, hydrophobic interactions, or the sharing of pi electrons due to aromaticity. Propofol, like honokiol, has a role not only as an anesthetic, but more recently as a neuroprotectant, anti-inflammatory, and anti-tumorigenic agent as well (57-59). It is likely that as further research is performed using propofol, honokiol, and other compounds with similar structure, more commonalities will be discovered among them, which will help to further define their mechanisms of action.

Honokiol is not entirely without risks, although its limited empirical application to humans at therapeutic doses has limited the evaluation of its side effect profile thus far. There are potential risks that can be expected, including increased bleeding and potential neurotoxicity at high doses. Honokiol has been found to be a potent inhibitor of arterial thrombosis, so it may be advisable to avoid honokiol in coagulopathic patients or in those where bleeding or hemorrhage may be of concern (13). These may include patients with hemorrhagic stroke, patients with hemorrhagic changes following ischemic stroke, patients on coumadin or therapeutic lovenox, and patients with clotting disorders such as

\section{REFERENCES}

1. Alonso-Castro AJ, Zapata-Bustos R, Dominguez F, Garcia-Carranca A, Salazar-Olivo LA. Magnolia dealbata Zucc and its active principles honokiol and magnolol stimulate glucose uptake in murine and human adipocytes using the insulin-signaling pathway. Phytomedicine (2011) 18(11):926-33. doi:10.1016/j. phymed.2011.02.015

2. Dominguez F, Chavez M, GardunoRamirez ML, Chavez-Avila VM, Mata M, Cruz-Sosa F. Honokiol and magnolol production by in vitro micropropagated plants of Magnolia dealbata, an endangered endemic Mexican species. Nat Prod Commun (2010) 5(2):235-40.

3. Dominguez F, Chivez M, GardunRamirez ML, Chavez-Avila VM, Mata M, Cruz-Sosa F. Production of honokiol and magnolol in suspension cultures of Magnolia dealbata Zucc. Nat Prod Commun (2009) 4(7):939-43.

4. Maruyama Y, Kuribara H. Overview of the pharmacological features of honokiol. CNS Drug Rev (2000) 6(1):35-44. doi:10.1111/j.15273458.2000.tb00136.x
5. Trapani G, Altomare C, Liso G, Sanna E, Biggio G. Propofol in anesthesia. Mechanism of action, structure-activity relationships, and drug delivery. Curr Med Chem (2000) 7(2):249-71. doi:10.2174/ 0929867003375335

6. Kuribara H, Kishi E, Hattori N, Okada M, Maruyama Y. The anxiolytic effect of two oriental herbal drugs in Japan attributed to honokiol from Magnolia bark. J Pharm Pharmacol (2000) 52(11):1425-9. doi:10.1211/0022357001777432

7. Kuribara H, Kishi E, Kimura M, Weintraub ST, Maruyama Y. Comparative assessment of the anxiolytic-like activities of honokiol and derivatives. Pharmacol Biochem Behav (2000) 67(3):597-601. doi: 10.1016/S0091-3057(00)00401-9

8. Kuribara H, Stavinoha WB, Maruyama Y. Honokiol, a putative anxiolytic agent extracted from Magnolia bark, has no diazepamlike side-effects in mice. J Pharm Pharmacol (1999) 51(1):97-103.

9. Kuribara H, Stavinoha WB, Maruyama Y. Behavioural pharmacological characteristics of honokiol, an anxiolytic agent present in extracts of Magnolia

hemophilia or von Willebrand's deficiency. And, while honokiol has been found to have neuroprotective effects at low doses, it has also been found to increase neuronal death in vitro at higher doses (100 $\mu \mathrm{M}$ applied directly to fetal cortical neurons) (38). This suggests a need to further study its pharmacokinetic and pharmacodynamic parameters in humans before unintentionally administering a potentially toxic dose of this compound. Although the pharmacodynamics and pharmacokinetics of honokiol have now been well-studied in rats, further studies need to be performed in humans before it can be widely administered (29, 60, $61)$. With modifications of its structure and methods of delivery helping to improve its functionality at multiple targets, including the GABA receptor and its subunits, serotonergic receptors, and members of the inflammatory cascade, honokiol stands as a promising new therapeutic agent for a variety of conditions.

\section{AUTHOR CONTRIBUTIONS}

AW, researched references, wrote the paper, assembled figures/tables; SPY, wrote the paper, added/checked references, assisted in assembling figures/tables; LW, wrote the paper, added/checked references, assisted in assembling figures/tables; PSG, wrote the paper, added/checked references, assisted in assembling figures/tables.

\section{ACKNOWLEDGMENTS}

This research was supported in part by the Foundation for Anesthesia Education and Research (FAER), the James S. McDonnell Foundation and a VA Career Development Award.

bark, evaluated by an elevated plus-maze test in mice. $J$ Pharm Pharmacol (1998) 50(7):819-26. doi:10.1111/j.2042-7158.1998. tb07146.x

10. Lin YR, Chen HH, Lin YC, Ko CH, Chan MH. Antinociceptive actions of honokiol and magnolol on glutamatergic and inflammatory pain. J Biomed Sci (2009) 16:94. doi:10. 1186/1423-0127-16-94

11. Qiang LQ, Wang CP, Wang FM, Pan Y, Yi LT, Zhang X, et al. Combined administration of the mixture of honokiol and magnolol and ginger oil evokes antidepressant-like synergism in rats. Arch Pharm Res (2009) 32(9):1281-92. doi:10.1007/ s12272-009-1914-6

12. Xu Q, Yi LT, Pan Y, Wang X, Li YC, Li JM, et al. Antidepressantlike effects of the mixture of honokiol and magnolol from the barks of Magnolia officinalis in stressed rodents. Prog Neuropsychopharmacol Biol Psychiatry (2008) 32(3):715-25.

13. Hu H, Zhang XX, Wang YY, Chen SZ. Honokiol inhibits arterial thrombosis through endothelial cell protection and stimulation of prostacyclin. Acta Pharmacol Sin
(2005) 26(9):1063-8. doi:10.1111/j. 1745-7254.2005.00164.X

14. Chang B, Lee Y, Ku Y, Bae K, Chung C. Antimicrobial activity of magnolol and honokiol against periodontopathic microorganisms. Planta Med (1998) 64(4):367-9. doi:10.1055/s-2006-957453

15. Ho KY, Tsai CC, Chen CP, Huang JS, Lin CC. Antimicrobial activity of honokiol and magnolol isolated from Magnolia officinalis. Phytother Res (2001) 15(2):139-41. doi: 10.1002/ptr.736

16. Kim YS, Lee JY, Park J, Hwang W, Lee J, Park D. Synthesis and microbiological evaluation of honokiol derivatives as new antimicrobial agents. Arch Pharm Res (2010) 33(1):61-5. doi:10.1007/ s12272-010-2225-7

17. Ko $\mathrm{CH}$, Chen $\mathrm{HH}$, Lin YR, Chan MH. Inhibition of smooth muscle contraction by magnolol and honokiol in porcine trachea. Planta Med (2003) 69(6):532-6. doi:10.1055/s2003-40654

18. Fried LE, Arbiser JL. Honokiol, a multifunctional antiangiogenic and antitumor agent. Antioxid Redox Signal (2009) 11(5):1139-48. doi: 10.1089/ARS.2009.2440 
19. Chen CM, Liu SH, Lin-Shiau SY. Honokiol, a neuroprotectant against mouse cerebral ischaemia, mediated by preserving $\mathrm{Na}+, \mathrm{K}+-$ ATPase activity and mitochondrial functions. Basic Clin Pharmacol Toxicol (2007) 101(2):108-16.

20. Cui HS, Huang LS, Sok DE, Shin J, Kwon BM, Youn UJ, et al. Protective action of honokiol, administered orally, against oxidative stress in brain of mice challenged with NMDA. Phytomedicine (2007) 14(10):696-700. doi:10. 1016/j.phymed.2007.03.005

21. Harada S, Kishimoto M, Kobayashi M, Nakamoto K, Fujita-Hamabe W, Chen $\mathrm{HH}$, et al. Honokiol suppresses the development of postischemic glucose intolerance and neuronal damage in mice. $J$ Nat Med (2012) 66(4):591-9. doi:10. 1007/s11418-011-0623-X

22. Hoi CP, Ho YP, Baum L, Chow AH. Neuroprotective effect of honokiol and magnolol, compounds from Magnolia officinalis, on beta-amyloid-induced toxicity in PC12 cells. Phytother Res (2010) 24(10):1538-42. doi:10.1002/ptr.3178

23. Hu Z, Bian X, Liu X, Zhu Y, Zhang $\mathrm{X}$, Chen S, et al. Honokiol protects brain against ischemia-reperfusion injury in rats through disrupting PSD95-nNOS interaction. Brain Res (2013) 1491:204-12. doi:10.1016/j. brainres.2012.11.004

24. Lin YR, Chen $\mathrm{HH}$, Ko $\mathrm{CH}$, Chan $\mathrm{MH}$. Neuroprotective activity of honokiol and magnolol in cerebellar granule cell damage. Eur J Pharmacol (2006) 537(1-3):64-9. doi: 10.1016/j.ejphar.2006.03.035

25. Liou KT, Lin SM, Huang SS, Chih CL, Tsai SK. Honokiol ameliorates cerebral infarction from ischemiareperfusion injury in rats. Planta Med (2003) 69(2):130-4. doi:10. 1055/s-2003-37707

26. Liou KT, Shen YC, Chen CF, Tsao $\mathrm{CM}$, Tsai SK. Honokiol protects rat brain from focal cerebral ischemiareperfusion injury by inhibiting neutrophil infiltration and reactive oxygen species production. Brain Res (2003) 992(2):159-66. doi:10. 1016/j.brainres.2003.08.026

27. Zhang P, Liu X, Zhu Y, Chen S, Zhou D, Wang Y. Honokiol inhibits the inflammatory reaction during cerebral ischemia reperfusion by suppressing NF-kappaB activation and cytokine production of glial cells. Neurosci Lett (2013) 534:123-7. doi: 10.1016/j.neulet.2012.11.052

28. Lee YJ, Lee YM, Lee CK, Jung JK, Han SB, Hong JT. Therapeutic applications of compounds in the Magnolia family. Pharmacol Ther (2011) 130(2):157-76.

29. Tsai TH, Chou CJ, Cheng FC, Chen CF. Pharmacokinetics of honokiol after intravenous administration in rats assessed using highperformance liquid chromatography. J Chromatogr B Biomed Appl (1994) 655(1):41-5. doi:10.1016/ 0378-4347(94)00031-X

30. Chen F, Wang T, Wu YF, Gu Y, $\mathrm{Xu} \mathrm{XL}$, Zheng $\mathrm{S}$, et al. Honokiol: a potent chemotherapy candidate for human colorectal carcinoma. World J Gastroenterol (2004) 10(23):3459-63.

31. Wang XH, Cai LL, Zhang XY, Deng LY, Zheng H, Deng CY, et al. Improved solubility and pharmacokinetics of PEGylated liposomal honokiol and human plasma protein binding ability of honokiol. Int J Pharm (2011) 410(1-2):169-74. doi:10.1016/j.ijpharm.2011.03.003

32. Gong C, Shi S, Wang X, Wang Y, Fu S, Dong P, et al. Novel composite drug delivery system for honokiol delivery: self-assembled poly(ethylene glycol)-poly(epsiloncaprolactone)-poly(ethylene glycol) micelles in thermosensitive poly(ethylene glycol)-poly(epsiloncaprolactone)-poly(ethylene glycol) hydrogel. J Phys Chem B (2009) 113(30):10183-8. doi:10.1021/jp902697d

33. Zheng X, Wang X, Gou M, Zhang J, Men K, Chen L, et al. A novel transdermal honokiol formulation based on Pluronic F127 copolymer. Drug Deliv (2010) 17(3):138-44. doi:10. 3109/10717541003604874

34. Wang X, Duan X, Yang G, Zhang $\mathrm{X}$, Deng L, Zheng $\mathrm{H}$, et al. Honokiol crosses BBB and BCSFB, and inhibits brain tumor growth in rat 9L intracerebral gliosarcoma model and human U251 xenograft glioma model. PLoS One (2011) 6(4):e18490. doi:10.1371/ journal.pone.0018490

35. Lin JW, Chen JT, Hong CY, Lin YL, Wang KT, Yao CJ, et al. Honokiol traverses the blood-brain barrier and induces apoptosis of neuroblastoma cells via an intrinsic bax -mitochondrion-cytochrome ccaspase protease pathway. Neuro Oncol (2012) 14(3):302-14. doi:10. $1093 /$ neuonc/nor217

36. Chang-Mu C, Jen-Kun L, ShingHwa L, Shoei-Yn LS. Characterization of neurotoxic effects of NMDA and the novel neuroprotection by phytopolyphenols in mice. Behav Neurosci (2010) 124(4):541-53. doi: $10.1037 / \mathrm{a} 0020050$
37. Esumi T, Makado G, Zhai H, Shimizu Y, Mitsumoto Y, Fukuyama Y. Efficient synthesis and structureactivity relationship of honokiol, a neurotrophic biphenyl-type neolignan. Bioorg Med Chem Lett (2004) 14(10):2621-5.

38. Fukuyama Y, Nakade K, Minoshima Y, Yokoyama R, Zhai H, Mitsumoto Y. Neurotrophic activity of honokiol on the cultures of fetal rat cortical neurons. Bioorg Med Chem Let (2002) 12(8):1163-6.

39. Praveen Kumar V, Gajendra Reddy R, Vo DD, Chakravarty S, Chandrasekhar S, Gree R. Synthesis and neurite growth evaluation of new analogues of honokiol, a neolignan with potent neurotrophic activity. Bioorg Med Chem Lett (2012) 22(3):1439-44. doi:10.1016/j.bmcl. 2011.12.015

40. Watanabe K, Watanabe H, Goto $\mathrm{Y}$, Yamaguchi $\mathrm{M}$, Yamamoto $\mathrm{N}$, Hagino K. Pharmacological properties of magnolol and honokiol extracted from Magnolia officinalis: central depressant effects. Planta Med (1983) 49(10):103-8. doi:10. 1055/s-2007-969825

41. Lin YR, Chen $\mathrm{HH}$, Ko $\mathrm{CH}$ Chan MH. Differential inhibitory effects of honokiol and magnolol on excitatory amino acidevoked cation signals and NMDAinduced seizures. Neuropharmacology (2005) 49(4):542-50. doi:10. 1016/j.neuropharm.2005.04.009

42. Matsui N, Takahashi K, Takeichi M, Kuroshita T, Noguchi K, Yamazaki $\mathrm{K}$, et al. Magnolol and honokiol prevent learning and memory impairment and cholinergic deficit in SAMP8 mice. Brain Res (2009) 1305:108-17. doi:10.1016/j. brainres.2009.09.107

43. Lee YJ, Choi DY, Yun YP, Han $\mathrm{SB}$, Kim HM, Lee $\mathrm{K}$, et al. Ethanol extract of Magnolia officinalis prevents lipopolysaccharideinduced memory deficiency via its antineuroinflammatory and antiamyloidogenic effects. Phytother Res (2012) 27(3):438-47. doi:10.1002/ ptr.4740

44. Squires RF, Ai J, Witt MR, Kahnberg P, Saederup E, Sterner O, et al. Honokiol and magnolol increase the number of $[3 \mathrm{H}]$ muscimol binding sites three-fold in rat forebrain membranes in vitro using a filtration assay, by allosterically increasing the affinities of low-affinity sites. Neurochem Res (1999) 24(12):1593-602. doi:10. 1023/A:1021116502548

45. Ai J, Wang X, Nielsen M. Honokiol and magnolol selectively interact with GABAA receptor subtypes in vitro. Pharmacology (2001) 63(1):34-41. doi:10.1159/ 000056110

46. Taferner B, Schuehly W, Huefner A, Baburin I, Wiesner K, Ecker GF, et al. Modulation of GABAAreceptors by honokiol and derivatives: subtype selectivity and structure-activity relationship. J Med Chem (2011) 54(15):5349-61. doi:10.1021/jm200186n

47. $\mathrm{Ku} \mathrm{TH}$, Lee YJ, Wang SJ, Fan $\mathrm{CH}$, Tien LT. Effect of honokiol on activity of $\operatorname{GAD}(65)$ and $\operatorname{GAD}(67)$ in the cortex and hippocampus of mice. Phytomedicine (2011) 18(13):1126-9. doi:10.1016/ j.phymed.2011.03.007

48. Alexeev M, Grosenbaugh DK, Mott DD, Fisher JL. The natural products magnolol and honokiol are positive allosteric modulators of both synaptic and extra-synaptic GABA(A) receptors. Neuropharmacology (2012) 62(8):2507-14. doi: 10.1016/j.neuropharm.2012.03.002

49. Qu WM, Yue XF, Sun Y, Fan $\mathrm{K}$, Chen CR, Hou YP, et al. Honokiol promotes non-rapid eye movement sleep via the benzodiazepine site of the GABA(A) receptor in mice. Br J Pharmacol (2012) 167(3):587-98. doi:10.1111/j.14765381.2012.02010.x

50. Lee IO, Kong MH, Kim NS, Choi YS, Lim SH, Lee MK. Effects of different concentrations and volumes of formalin on pain response in rats. Acta Anaesthesiol Sin (2000) 38(2):59-64.

51. Lin YR, Chen $\mathrm{HH}$, Ko $\mathrm{CH}$, Chan $\mathrm{MH}$. Effects of honokiol and magnolol on acute and inflammatory pain models in mice. Life $S c i$ (2007) 81(13):1071-8. doi:10.1016/ j.lfs.2007.08.014

52. Chao LK, Liao PC, Ho CL, Wang EI, Chuang CC, Chiu HW, et al. Antiinflammatory bioactivities of honokiol through inhibition of protein kinase $C$, mitogen-activated protein kinase, and the NF-kappaB pathway to reduce LPS-induced TNFalpha and NO expression. J Agric Food Chem (2010) 58(6):3472-8. doi:10. 1021/jf904207m

53. Li CY, Chao LK, Wang SC, Chang HZ, Tsai ML, Fang SH, et al. Honokiol inhibits LPSinduced maturation and inflammatory response of human monocytederived dendritic cells. J Cell Physiol (2011) 226(9):2338-49. doi:10. $1002 /$ jcp. 22576

54. Murakami Y, Kawata A, Seki Y, Koh T, Yuhara K, Maruyama T, et al. Comparative inhibitory 
effects of magnolol, honokiol, eugenol and bis-eugenol on cyclooxygenase- 2 expression and nuclear factor-kappa B activation in RAW264.7 macrophage-like cells stimulated with fimbriae of Porphyromonas gingivalis. In vivo (2012) 26(6):941-50.

55. Crane C, Panner A, Pieper RO, Arbiser J, Parsa AT. Honokiolmediated inhibition of PI3K/mTOR pathway: a potential strategy to overcome immunoresistance in glioma, breast, and prostate carcinoma without impacting $\mathrm{T}$ cell function. $J$ Immunother (2009) 32(6):585-92. doi:10.1097/CJI.0b013e3181a8efe6

56. Lee JD, Lee JY, Baek BJ, Lee BD, Koh YW, Lee WS, et al. The inhibitory effect of honokiol, a natural plant product, on vestibular schwannoma cells. Laryngoscope
(2012) 122(1):162-6. doi:10.1002/ lary. 21781

57. Wang P, Chen J, Mu LH, Du QH, Niu $\mathrm{XH}$, Zhang M-Y. Propofol inhibits invasion and enhances paclitaxelinduced apoptosis in ovarian cancer cells through the suppression of the transcription factor slug. Eur Rev Med Pharmacol Sci (2013) 17(13):1722-9.

58. Yang SC, Chung PJ, Ho CM, Kuo CY, Hung MF, Huang YT, et al. Propofol inhibits superoxide production, elastase release, and chemotaxis in formyl peptideactivated human neutrophils by blocking formyl peptide receptor 1 . J Immunol (2013) 190(12):6511-9. doi:10.4049/jimmunol.1202215

59. Wang H, Wang G, Wang C, Wei Y, Wen Z, Zhu A. The early stage formation of PI3K-AMPAR GluR2 subunit complex facilitates the long term neuroprotection induced by propofol post-conditioning in rats. PLoS One (2013) 8(6):e65187. doi: 10.1371/journal.pone.0065187

60. Chen SZ, Jia H, Wu YH, Wang H. Pharmacokinetics of honokiol in rats. Beijing Da Xue Xue Bao (2004) 36(1):41-4.

61. Su WJ, Huang X, Qin E, Jiang L, Ren P. Pharmacokinetics of honokiol in rat after oral administration of cortex of Magnolia officinalis and its compound preparation Houpu Sanwu Decoction. Zhong Yao Cai (2008) 31(2):255-8.

Conflict of Interest Statement: The authors declare that the research was conducted in the absence of any commercial or financial relationships that could be construed as a potential conflict of interest.
Received: 29 July 2013; paper pending published: 11 August 2013; accepted: 26 August 2013; published online: 11 September 2013.

Citation: Woodbury A, Yu SP, Wei L and García P (2013) Neuro-modulating effects of honokiol: a review. Front. Neurol. 4:130. doi: 10.3389/fneur.2013.00130 This article was submitted to Neuropharmacology, a section of the journal Frontiers in Neurology.

Copyright (c) 2013 Woodbury, Yu, Wei and García. This is an open-access article distributed under the terms of the Creative Commons Attribution License (CC $B Y)$. The use, distribution or reproduction in other forums is permitted, provided the original author(s) or licensor are credited and that the original publication in this journal is cited, in accordance with accepted academic practice. No use, distribution or reproduction is permitted which does not comply with these terms. 